\title{
Ocular and Facial Maldevelopment: The Role of Neural Crest
}

\author{
L. BUTLER and H. E. WILLSHAW \\ Birmingham
}

\begin{abstract}
Summary
Three children are described who show a spectrum of clinical abnormalities affecting their eyes and non ocular tissues. These entities are best explained as disorders of neural crest migration and once recognised should lead to a search for other systemic developmental disorders.

The mechanism of combined facial skeleton and eye malformation is discussed in the light of our current understanding of ocular embryology, and the justification for considering these and other entities as examples of Neurocristopathies is explored.
\end{abstract}

Neural crest tissue consists of a mass of pluripotential cells, arising from ectoderm situated along the dorsal surface of the developing neural tube. As the neural folds fuse to form brain and spinal cord, both cephalic and truncal neural crest begin to migrate extensively, ultimately contributing to such diverse tissues as autonomic ganglia, cartilage and bone, smooth muscle ${ }^{1}$ and from an ocular standpoint, uveal melanophores and anterior chamber structures. ${ }^{2}$ Both the cellular and extracellular microenvironments critically affect the development and migration of crest tissue, the biochemical nature of the extracellular matrix through which it migrates appearing to be of particular importance. Furthermore the migration has to be both spatially and temporally patterned to achieve a normal phenotype. ${ }^{3}$

Abnormal behaviour of neural crest tissue has been considered to give rise to developmental disorders in one of four ways. ${ }^{4}$

(1) Defects in neural crest formation.

(2) Defects in neural crest migration.

(3) Defects in cell proliferation.

(4) Disorders of cellular differentiation.

In addition recent studies have suggested that the process of cell death and subsequent remodelling is important in normal mor- phogenesis ${ }^{5}$ and certain anterior chamber anomalies may result from abnormal cell death. ${ }^{6}$ In 1974 the term Neurocristopathy was coined to describe those disorders which had as their unifying feature the maldevelopment of structures derived from neural crest. ${ }^{7}$ We describe three children with a spectrum of developmental abnormalities which allow them to be classified as Neurocristopathies.

\section{Case Reports}

(1) JG presented at age 8 years 2 months with photophobia. His mother, brother and maternal grandfather were known to have mandibulo facial dysostosis (Treacher-Collins syndrome), and JG showed similar, though mild, facial features (Fig. 1). He also showed marked fundus hypopigmentation and a dysplastic right optic nerve (Fig. 2).

(2) PW was diagnosed shortly after birth as having Oculo-auriculo-vertebral dysplasia (Goldenhaar's syndrome). He showed several systemic features including pre-auricular skin tags, a sinus on his left cheek, clefting of his soft palate, unilateral mandibular hypoplasia and renal cysts. He was initially found to have a lipodermoid with associated sclero-cornea on the left, but as slit lamp microscopic examination has become easier, it has become apparent that he also has left sided Peter's anomaly, with anterior synychiae to the margins of a posterior, central, corneal opacity (Fig. 3). 
(3) MR was born to unrelated Asian parents at 38 weeks gestation. At birth he showed the features of Robert's syndrome with gross midline lip and palatal clefting, tetraphocomelia, abnormal genitalia and radiological evidence of a large midline defect in the frontal bones. In addition he had bilateral corneal opacification and roving eye movements, with no evidence of vision (Fig. 4). ERGs were normal bilaterally and he underwent right penetrating keratoplasty at seven months of

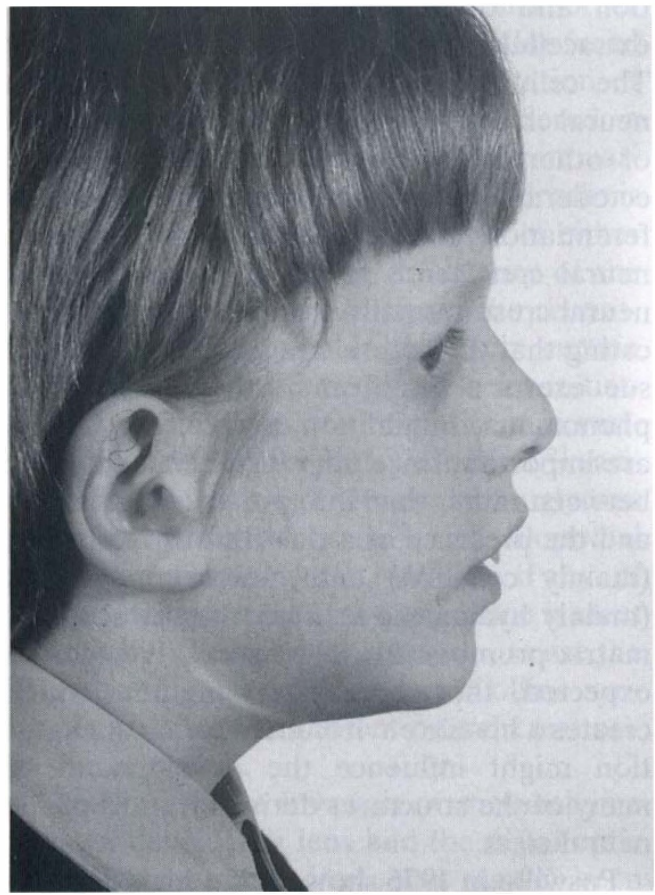

Fig. 1. JG Typical maxillary hypoplasia.

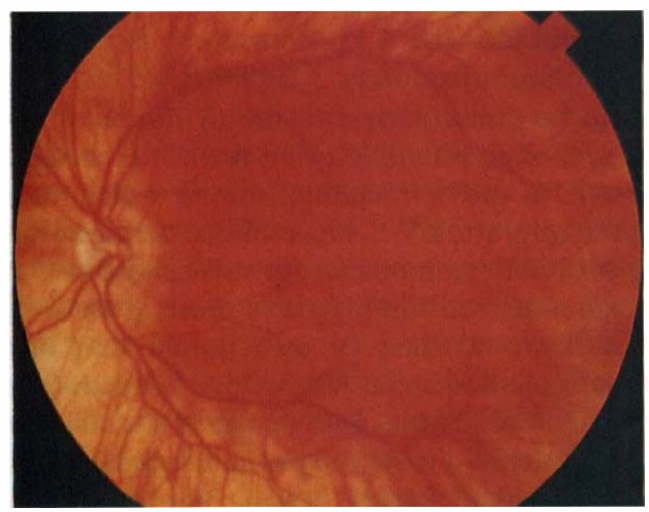

Fig. 2. Hypopigmented fundus with mild disc dysplasia. age, with an initially good result, but failure of the graft 4 months later following a non specific viral illness. He has subsequently been lost to follow up.

Histology of the excised corneal disc showed an abnormality of the anterior portion of the stroma, with an absent Bowman's layer, increased numbers of keratocytes, but apparently normal endothelium and Descemet's membrane.

\section{Discussion}

Much of the information available on the behaviour of neural crest tissue is derived
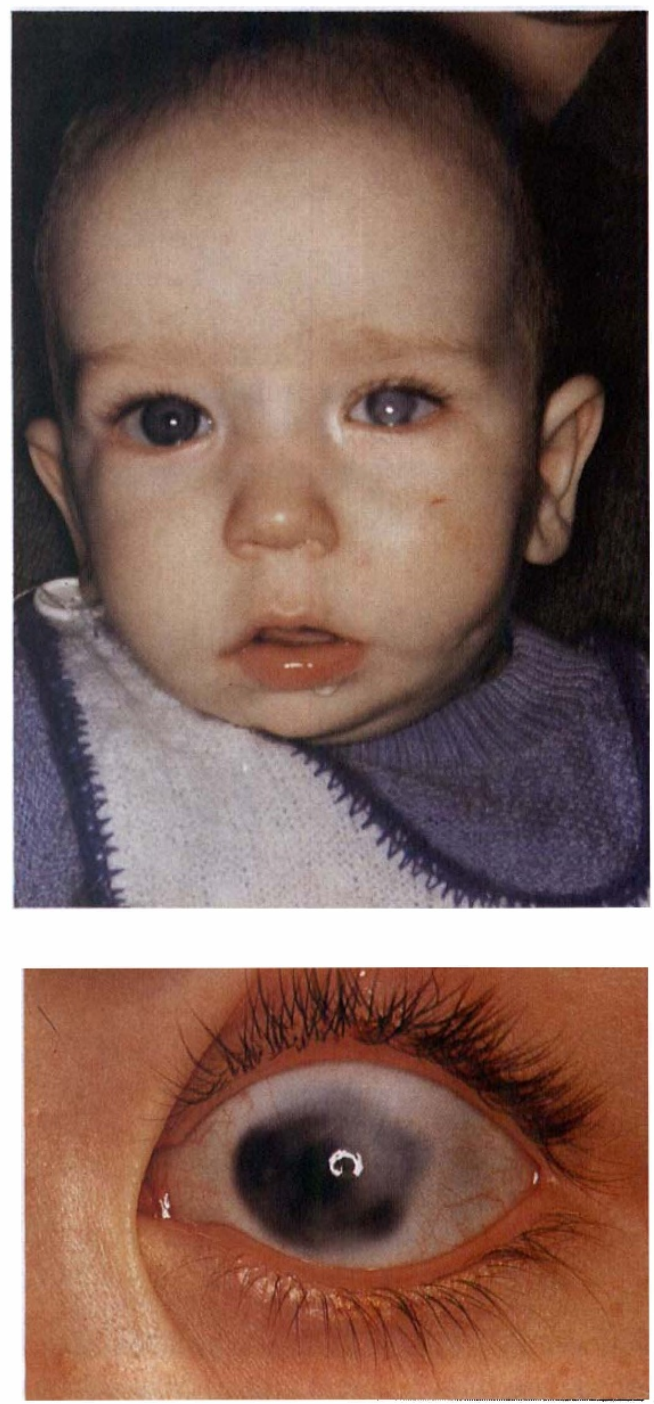

Fig. 3. PW Goldenhaar's syndrome plus Peter's anomaly. 

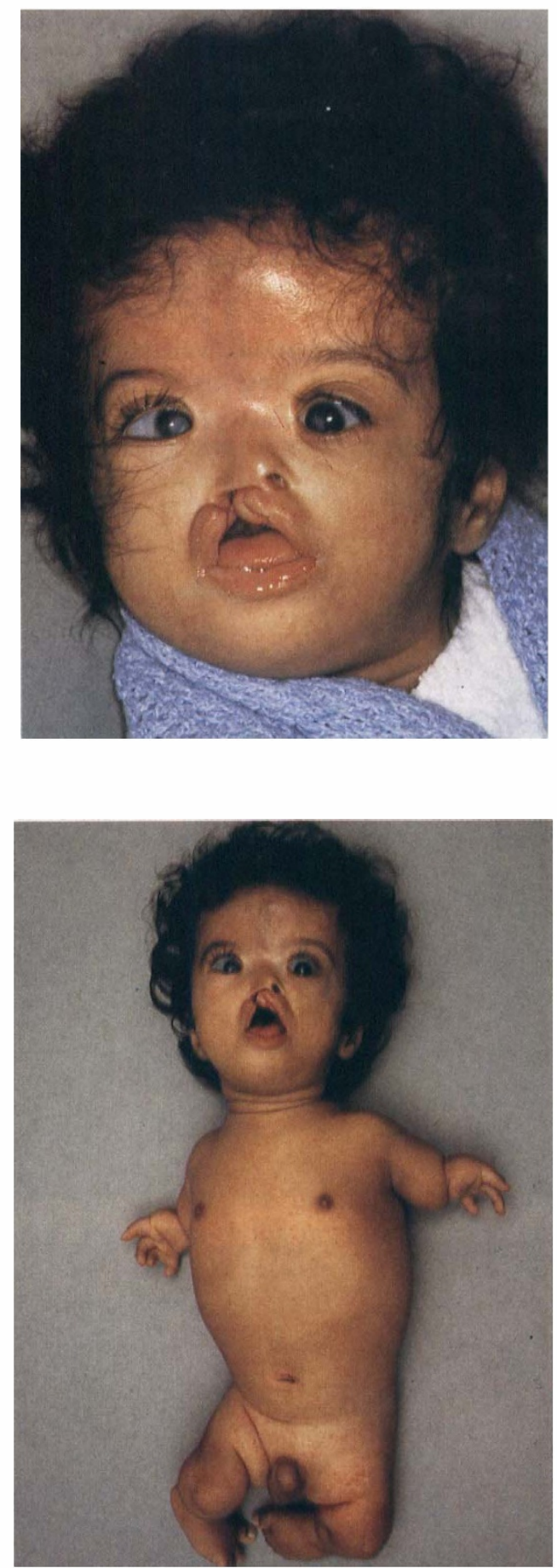

Fig. 4. Robert's syndrome, midline clefting, tetraphocomelia, abnormal genitalia, corneal opacification. from work on avian and amphibian species. ${ }^{8,9,10}$ Extrapolation to human development has in the past been questioned, ${ }^{11}$ but the recognition of clinical examples such as these three children, argues strongly for a similar pattern in man. Elegant studies using $3 \mathrm{H}$ thymidine labelled neural crest $^{12}$ and implantation of foreign crest material which can be identified histologically ${ }^{13}$ have elucidated the patterns of migration and development. Both cellular and extracellular influences are brought to bear. The cellular factors are related to adjacent neural crest cells and also the surface features of other cellular elements such as surface ectoderm, neuroectoderm etc. ${ }^{14}$ The differentiation and migration of transplanted neural crest tends to adopt the patterns of neural crest normally found in that site, indicating that the nature of adjacent cellular tissue exerts a significant influence on these phenomena. In addition extracellular factors are important since migration tends to occur between rather than into pre-existing tissues, and the presence of a rich fibrous meshwork (mainly collagen) and glycosaminoglycans (mainly hyaluronic acid) in the extracellular matrix promote this migration. ${ }^{15}$ It might be expected, therefore, that something which creates a hostile environment for crest migration might influence the development of many of the structures derived from cephalic neural crest.

Poswillo in 1976 showed that high doses of Vitamin A administered at the appropriate time were capable of reproducing the features of the Treacher Collins syndrome, (Mandibulo facial dysostosis). ${ }^{16} \mathrm{He}$ considered the injection of 100,000 IU of Vitamin A to be directly toxic to the neural crest tissue, though others felt that it was the modification of the extracellular matrix which inhibited migration. ${ }^{17}$ Since a failure of migration is probably responsible for this syndrome, ${ }^{4} \mathrm{a}$ toxic effect on the matrix is more attractive, but it would then be anticipated that one would see accompanying ocular features (the maxilla, mandible and ocular determinants are all derived from the cephalic neural crest, though the facial bones are primarily mesencephalic in origin, whilst the ocular tissues are predominantly prosencephalic). ${ }^{18}$ 
Our first case (JG) demonstrates this expected association. Cotlier et al described a similar association, ${ }^{19}$ but their patient showed the facial features of hemifacial microsomia which has not so clearly been shown to result from defective crest migration. Our patient has the typical features of the Treacher Collins syndrome, ${ }^{20}$ and in addition has uveal hypopigmentation (both iris and choroid). Because Treacher Collins is a dominantly inherited condition, and other members of JG's family with a similar facial appearance do not have depigmentation of the choroid, this could be considered a chance association. However, significant variation in the manifestation of the syndrome is common $^{21}$ and if this is on the basis of either a difference in the timing or severity of the insult then one would anticipate the recruitment of other susceptible tissues in certain instances. The factors responsible for initiating and substaining crest migration are various and include intercellular adhesion, ${ }^{22}$ variations in the sulphated glycose aminoglycans in the extracellular tissue ${ }^{23}$ and filopodial connections between cells. ${ }^{24}$ Which, if any, of the factors important in cell migration is most affected by Vitamin $A$ is unknown, as are the factors acting in the Treacher Collins syndrome, but that they are of neural crest origin seems certain.

The three stage invasion of mesenchyme between developing lens and the distal optic vesicle, by neural crest, has again been demonstrated using both labelled autogenous tissue, and transplanted Quail tissue. The first wave gives rise to corneal endothelium, the second to corneal keratocytes (which then secrete collagen), and the third to iris stroma. ${ }^{25}$ Cell death and remodelling are also important in anterior chamber development, ${ }^{26}$ and Waring has produced a schematic representation of the recognised anomalies of anterior segment development, illustrating their origin in failure of these various processes. ${ }^{27}$ Riegers syndrome with its multisystem involvement (including skeleton, dentition etc) should almost certainly be classified as a Neurocristopathy, and our second patient $\mathrm{PW}$ demonstrates a further entity with facial skeleton and ocular involvement.
He shows all the classic features of the Goldenhaar syndrome ${ }^{28}$ but in addition, the eye ipsilateral to his mandibular hypoplasia also shows the changes of Peter's anomaly. Peter's anomaly is another, more localised defect of neural crest migration, which once again has recently been reproduced in animals by exposure to human teratogens. ${ }^{29}$ However, the features of Goldenhaar's syndrome can be reproduced by creating a haematoma at the apex of the first branchial $\operatorname{arch}^{17}$ and has been considered to be a mechanical phenomenon. Whether some physical obstruction to migration is possible remains unexplored, but would offer an explanation of the association found in PW.

Our third and most profoundly affected child shows extensive structural abnormalities, the unifying feature being their neural crest origin. The phocomelia is particularly important in this respect, since studies undertaken to explain the toxic effects of the drug Thalidomide ${ }^{30}$ showed that it was the failure of colonisation of the developing limb bud by neural crest tissue which gave rise to the phocomelia. We have previously reported a child with Thalidomide toxicity who showed features of the Treacher Collins syndrome ${ }^{20}$ and this boy with his gross corneal changes is a similar problem. He showed no other anterior segment abnormalities, suggesting an effect on the first or second migrating waves of crest tissue, however the changes seen histologically affected, principally, the anterior corneal tissue with excessive numbers of keratocytes seen in the stroma.

These cases have each seemed best explained by disordered migration, but other anomalies exist which result from defective crest formation (brain-eye-face malformations) defective proliferation (Waardenburg's syndrome) or disordered differentiation including the processes of cell death and remodelling (Aniridia). The clinical importance of recognising these entities and their origin is to become aware of the potential for multisystem involvement. Such observations also serve a useful role in supporting the experimental animal studies, and helping to validate them. 


\section{References}

${ }^{1}$ Weston JA: A radioautographic analysis of the migration and localisation of trunk Neural crest in the chick. Dev Biol 1963, 6: 279-310.

2 Johnson MC, Noden DM, Hazelton RD et al.: Origins of avian ocular and periocular tissues. Exp Eye Res 1979, 29: 27-43.

${ }^{3}$ Noden DM: Interactions directing the migration and cytodifferentiation of avian neural crest cells. In Specificity of Embryological interactions (1978) ed Garrod DR Chapman \& Hall London

${ }^{4}$ Johnston MC: Regional embryology: aspects relevant to the embryogenesis of craniofacial malformations. In Proc of the Int Conference of craniofac malformations (1974) Converse JM, Pruzansky S eds Mosby CV.

5 Garcia-Porrero JA, Collado JA, Ojeda JL: Cell death during detachment of the lens rudiment from ectoderm in the chick embryo. Anat Rec 1979, 193: 791-804

${ }^{6}$ Bahn CR, Falls HF, Varley GA, Meyer RF et al. : Classification of corneal endothelial disorders based on neural crest origin. Ophthalmol 1984, 91: 558-63.

7 Bolande

${ }^{8}$ di Virgilio G, Lavenda N, Worden JL: Sequences of events in neural tube closure and the formation of neural crest in the chick embryo. Acta Anat 1967, 68: 127-46.

${ }^{9}$ Lehman F: Further studies on the morphogenetic role of the somites in the development of the nervous system of amphibians. The arrangement and differentiation of spinal ganglia in Pleurodeles Waltii. J Exp Zool 1927, 49: 93-142

${ }^{10}$ Borack L: Gene action on proliferation and migration in the developing neural crest of black and white Axolotls Ambystoma mexicanum, Shaw. J Exp Zool 1971, 179: 289-98.

${ }^{11}$ Hay ED: Development of the vertebrate cornea. Int Rev Cytol 1980, 63: 263-322.

12 Johnston MC: A radioautographic study of the migration and the fate of cranial neural crest cells in the chick embryo. Anat Rec 1966, 156: 143-56.

13 Noden DM: Cytodifferentiation in heterotopically transplanted neural crest cells. J Gen Physiol. 1976, 68: 13a.

${ }^{14}$ Fisher $\mathbf{M}$ and Solursh M: Glycosaminoglycan localisation and role in maintenance of tissue spaces in the early chick embryo. $J$ Embryol Exp Morph 1971, 42: 195-207.

15 Hay ED and Meier S: Glycosaminoglycan synthesis by embryonic inductors: neural tube, notochord and lens. J Cell Biol 1974, 62: 889-98.

${ }^{16}$ Poswillo D: Pathogenesis of craniofacial syn- dromes exhibiting colobomata. Trans Ophthalmol Soc UK 1976, 96: 69-72.

${ }^{17}$ Hassell JR, Greenberg JH, Johnston MC: Inhibition of cranial neural crest development by Vitamin A in the cultured chick embryo. $J$ Embryol Exp Morphol 1977, 39: 267-71.

18 Noden DM: An analysis of the migratory behaviour of avian cephalic neural crest cells. Dev Biol 1975, 42: 106-30.

${ }^{19}$ Cotlier E and Azghadyn A: Mandibulofacial dysostosis (hemifacial microsomia) with cutaneous angiomas and choroidal depigmentation - a new syndrome. Ophthal Paed and Genet 1981, 1: 3-16.

20 Willshaw HE and Al-Ashkar F: The Branchial Arch syndromes. Trans Ophthalmol Soc UK 1983, 103: 331-337.

21 Grabb WC: The first and second branchial arch syndromes. Plastic and Reconst Surg 1965, 36: 485-508.

22 Ebendal T: Extracellular matrix fibrils and cell contacts in the chick embryo. Cell Tiss Res 1977, 175: 439-58.

${ }^{23}$ Masnasek FJ and Cohen AM: Anionic glycopeptides and glycosaminoglycans synthesized by embryonic neural tube and neural crest. Proc Natn Acad Sci USA 1977, 74: 1057-61.

${ }^{24}$ Bancroft $M$ and Bellairs $R$ : The neural crest cells of the trunk region of the chick embryo studied by SEM and TEM. Zoon 1976, 4: 7385.

${ }^{25}$ Hay ED and Revel JP: Fine structure of the developing avian cornea. Monographs in Devel Biol Vol 11969 Wolsky A, Chen PS eds S Krager AG Basel

${ }^{26}$ Garcia-Porrero JA, Colvee E, Ojeda JL: The mechanisms of cell death and phagocytosis in the early chick lens morphogenesis; A scanning electron microscopy and cytochemical approach. Anat Rec 1984, 208: 123-236.

27 Waring G, Rodrigues M, Laibson P: Anterior chamber cleavage syndrome: A stepladder classification. Survey Ophthalmol 1975, 20: 333.

${ }^{28}$ Goldenhaar M: Associations malformations de l'oeil et de l'oreille en particular le syndrome dermoide epibulbaire - appendices auricularies - fistula auris congenita et ses relations avec la dysostose mandibulofaciale. J Genet Hum 1952, 1: 243-82.

${ }^{29}$ Cook CS and Sulik KK: Keratolenticular dysgenesis (Peter's anomaly) as a result of acute embryonic insult during gastrulation. $J$ Paed Ophthalmol and Strab 1988, 25: 60-6.

${ }^{30}$ McCredie J, Cameron J, Shoobridge R: Congenital malformations and the neural crest. Lancet 1978, 2: 761-3. 